\title{
Giros EM FALSO NO DEBATE DA TEORIA ${ }^{1}$
}

\section{Fabio Akcelrud Durão}

(LIMA, Luiz Costa. Teoria da literatura em suas fon-

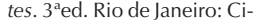
vilização Brasileira, 2002. vol.1, 7.)
I

Teoria da literatura em suas fontes, o primeiro e único reader do gênero no Brasil, traz no prefácio de sua última edição um comentário surpreendente. Diz Luiz Costa Lima, responsável pela coleção:

A principal razão da mudança [das ediçôes anteriores em relação a esta] tem a ver com a própria reflexão teórica. Ao passo que as décadas de 1960 a 1980 conheceram uma fantástica proliferação de direçōes teóricas, ao lado da não menos notável ressurreição de nomes que haviam estado esquecidos [...] a década de 1990 tem-se caracterizado ou pela consolidação ou desdobramento daquelas correntes ou pelo surgimento de rumos - os estudos sobre gênero, sobre as minorias sexuais, a literatura pós-colonial, o papel dos media, os genericamente chamados "cultural studies" - que não se notabilizam particularmente por algum vigor teórico. Pode-se mesmo afirmar que a reflexão teórica do objeto literário deixou de estar na crista da onda, passando a ser vista sob a suspeita de não ser politicamente correta.

Constatar a nulidade da produção de uma disciplina por uma década equivale a pronunciá-la morta. Esse extremado julgamento implícito é ao mesmo tempo verdadeiro e falso. Falso, porque não é verdade que a reflexão teórica tenha desaparecido nos anos 90 (para não mencionar que o desenvolvimento do trabalho de teóricos já consagrados poderia ter sido levado em consideração na revisão da antologia, assim como a produção de autores nacionais). Autores como Slavoj Žižek e Judith Butler começaram a publicar seus textos mais importantes nesta década; além disso, não se pode dizer que o trabalho de Gayatri Spivak ou Homi Bhabha não tenha um impulso teórico; pelo contrário, muito da recente crítica póscolonial ou queer tem sido criticado justamente por um excesso de teoria, tem sido visto como desnecessariamente difícil e abstrusa. No entanto, o veredicto de Costa Lima torna-se absolutamente verdadeiro quando se percebe que a ênfase do texto de introdução ao reader não está na teoria literária, mas na teoria literária, aquele campo de estudos que se caracterizava pela relação, ainda que in-

\footnotetext{
${ }^{1}$ Gostaria de agradecer aos professores Marcos Siscar e Paulo Franchetti pela cuidadosa leitura do texto e valiosas críticas.
} 
direta, alusiva, postergada, ou mesmo prometida, com a literatura. Mesmo que não a nomeie assim, Costa Lima registra, aqui, a passagem da teoria literária para a Teoria, um processo polêmico e contraditório, com implicaçôes epistemológicas e institucionais seriíssimas, e que por isso mesmo necessita urgentemente ser pensado com um mínimo de distanciamento e imparcialidade.

A emergência da Teoria é um fenômeno intrinsecamente norte-americano, e é no contexto da academia estadunidense que ela deve ser primeiramente entendida - e a isso retornaremos no final. Mas tal vinculação a um lugar e seu conjunto de instituiçôes não significa que não haja implicaçôes para o ambiente intelectual brasileiro; pelo contrário, a Teoria se faz sentir de diferentes maneiras: nas bibliografias de cursos de pós-graduação em Letras, que não incluem literatura, na preponderância do discurso crítico sobre seu objeto - quando se lê Benjamin sem Goethe, Bakhtin sem Rabelais ou Dostoievski, Deleuze sem Proust ou Kafka etc. -, ou na subordinação do cânone àquilo que podem dizer as novas teorias, como no caso da literatura pós-colonial, que freqüentemente parece apenas servir de exemplo para argumentos anteriores à leitura. A Teoria consolidou-se, quase naturalmente, com a crescente complexidade adquirida pelos aparatos explicativos, os meta-discursos da literatura. Já para o estruturalismo, a semiótica, a psicanálise ou o marxismo não era necessário voltar-se unicamente para os textos literários, e essa independência potencial só fez aumentar com o advento das novas correntes críticas, que podem se aplicadas ao horizonte das chamadas práticas significantes. Na Teoria, o estatuto do literário é incerto: se, por um lado, quase todos os grandes teóricos foram grandes leitores literários, por outro, a literatura não é de forma alguma indispensável. ${ }^{*}$

Uma outra maneira de se dizer isso é observar que a Teoria é uma nova formação discursiva caracterizada por uma crescente intransitividade. Mais do que "campo" ou "área", a metáfora mais adequada para descrevê-la talvez fosse a de uma nebulosa, na qual oscilam matéria e energia. A Teoria não tem objeto específico, pois dispõe-se a ler tudo, de épicos do século XVII ao Pato Donald; não tem uma fundamentação conceitual inequívoca, que pudesse pautar sua metodologia, pois é constituída por códigos (feminismo, estruturalismo, semiótica, psicanálise, desconstrução etc.) que podem ser mobilizados conjuntamente ou simplesmente existir lado a lado; por fim, ela faz surgir, em oposição ao erudito ou especia-
" (DURÃO, Fabio Akcelrud. "On the rise of Theory: promisses, shortcomings and the place of literature". American British and Canadian Studies, Sibiu (Romênia) v. 8, 2007: 10-21.)

(MATTELART, Armand, DORFMAN, Ariel. Para ler o Pato Donald: Comunicação de massa e colonialismo. Trad. Álvaro de Moya. Rio de Janeiro: Paz e Terra, 1977.) 
(DURÃO, Fabio Akcelrud. "Breves observações sobre a teoria, suas contradições e o Brasil" Revista de Letras, São José do Rio Preto, v. 44, n. 1 , 2004: 81-95.)
(CULLER, Jonathan. "Comment on the Norton Anthology of Theory and Criticism". Symploke 11.1-2., 2003: 242.)

(BOXER, Sarah. "How Crit Finally Won Out Over Lit". The New York Times, Nova York, 19 abril. 2001. B, 11.) (RICHTER, David. "Hyping the Norton - Comment on the Norton Anthology of Theory and Criticism". Symploke 11.1-2.) lista, a figura do Teórico, um pesquisador de alta mobilidade, capaz de se adaptar aos assuntos mais díspares e de incorporar as articulações conceituais mais novas. No entanto, essa liberdade em relação a objetos, metodologias e posições enunciativas é em grande medida desmentida pela realidade: os objetos ficam sujeitos à lógica da moda; as abordagens parecem já designar de antemão aquilo que se verá nos textos; como resultado, o Teórico converte-se em uma figura ao mesmo tempo negativamente fluida, por acompanhar as modas, e rígida, por sobredeterminar seus objetos. * O quadro é, sem dúvida, conflitante e complexo, principalmente porque as duas reações mais comuns a ele são igualmente insatisfatórias, funcionando como um parafuso que gira em falso sem levar a lugar nenhum. Por um lado, não se pode ignorar a situação de crise na qual a Teoria se encontra, os becos sem saída aos quais tende a levar; por outro, não é possível fazer uma tábula rasa e voltar à época pré-teórica, como se a falta de teoria, agora, já não se configurasse ela mesmo como uma teoria. Em suma: nem o pseudovanguardismo teórico, nem o moralismo do retorno à pureza do literário - nem um meio termo. Este texto procura reconstituir minimamente a tensão entre essas duas posições em um recente debate nos EUA, desencadeado pela publicação de dois grandes livros.

A Norton Anthology of Criticism and Theory (note-se a ausência de literary) foi publicada em 2001; um volume com 2.660 páginas, ela pode ser vista como um marco no processo de canonização da Teoria. Sua editora é a principal empresa do ramo no mundo anglófono, mas é apenas em parte ao prestígio da Norton que se pode atribuir o impacto do livro em resenhas e jornais. Se para alguns se trata de uma coleção que "dificilmente será ultrapassada como ponto de referência e recurso pedagógico", " para outros o gênero bibliográfico do livro cria contradiçôes com seu assunto: oferece-se uma paráfrase do argumento contra as paráfrases, apresenta-se a biografia de Barthes e Foucault, que escreveram sobre a morte do autor, institucionalizam-se textos que defendem a desinstitucionalização da teoria, ${ }^{2}$ incluem-se argumentos de Adorno \&

${ }^{2}$ Cf. Ngugi Wa Thiong'O, Taban Lo Liyong, Henry Owour-Anyumba. "On the abolition of the English Department". "The machinery for determining the choice of texts and their interpretation" is "an integral part of the imperialism and domination in the neo-colonial phase." [in LEITCH et al. 2001, p.2092-2097] 
Horkheimer contra a indústria cultural neste produto de (alta) indústria cultural. ${ }^{3}$ Brown, por outro lado, alerta para as ausências, que, se são inevitáveis nesse tipo de livro, também apontam para seu viés específico: "Os noventa e oito autores falecidos (noventa homens e oito mulheres) não incluem Bachelard, Blanchot, Bloch, Boethius, Boileau, Cícero, Croce, Diderot, Dilthey, Empson, Gadamer, Goethe, Herder, Humboldt, Langer, Luhmann, Ortega, Paz, Ricouer, Rousseau, nem Schlegel, Schopenhauer, Shklovski, Spitzer, Taine." (Note-se que para a letra "A" faltou Auerbach.) Essas faltas são em parte resultado do anglocentrismo do volume: "Dos 148 autores, 80 escreveram em inglês, 28 em francês, 18 em alemão, 6 em italiano, 3 em russo, 5 em grego, 7 em latim e 1 (Maimonides) em árabe. Espantosamente, não há um único texto originariamente escrito em espanhol, e apenas Gramsci representa a cultura italiana desde Vico."*

Mas a estranheza maior surge do choque entre o tratamento editorial e a natureza do material trabalhado. Pois é no mínimo curioso perceber que todo aquele aparato textual a que se está acostumado a encontrar nas antologias literárias seja transferido agora para a crítica e a teoria: introduções, contextualizações, notas explicativas, cronologias, biografias, influências e bibliografias secundárias (terciárias?) ajudam a fazer da Teoria algo em si, um campo praticamente autônomo. A própria organização do livro é interessante. Um primeiro índice lista os autores, de Górgias a Judith Butler, por data de nascimento; a ele somam-se outros quatro tipos de classificação, na ordem de apresentação: a. escolas e movimentos modernos e contemporâneos; b. gêneros; c. período históricos, assuntos e tópicos. Por sua organização, o primeiro e último são os mais importantes e atestam a ênfase dada pela antologia ao atual, o que é confirmado pelo espaço reservado para cada época. Seguindo a contagem de Marshall, " apenas 148 páginas são dedicadas à Antiguidade greco-romana; 177 à Idade Média; 99 à Renascença; 35 ao século XVII; 151 ao XVIII; 341 ao XIX; 543 ao velho século XX (Freud a Frye); e 1067 a autores contemporâneos (de Barthes a Moulthrop), dois quintos do total. As escolas e movimentos, listados alfabeticamente em inglês, compreendem: Estudos Culturais; Desconstrução e Pós-estruturalismo; Teoria e Crítica Feminista; Formalismo; Crítica Gay e Lésbica e Teoria Queer; Marxis-

\footnotetext{
${ }^{3}$ Para a resposta do editor geral cf. Leitch (2003). Symploke, Lincoln: vol. 11: 1-2, pp. 249-253.
}

" (BROWN, Marshall. "Theory without Method, Criticism without Voice". Pedagogy: Critical Approaches to Teaching Literature, Language, Composition and Culture, Durham, NC, v. 3, n. 3, 2003: 452.)

" (MARSHALL, Donald G. "Shooting Niagara" Pedagogy, v. 3, Issue 3, outono 2003: 464) 
mo; Novo Historicismo; Fenomenologia e Hermenêutica; Teoria e Crítica Pós-Colonial; Psicanálise; Estudos de Raça e Etnicidade; Teoria de Reação do Leitor [Reader Response Theory]; Estruturalismo e Semiótica. ${ }^{4}$ E o mesmo se dá em relação aos temas. São eles, de novo em ordem alfabética segundo o inglês: estética, autoria, o corpo, o cânone/tradição, defesas da crítica, gênero sexual e sexualidade, ideologia e hegemonia, a institucionalização dos estudos literários, ${ }^{5}$ teoria da interpretação, linguagem, o moderno, a narrativa, o pós-moderno, representação e realismo, retórica, subjetividade/ identidade, o vernacular e a nacionalidade, a literatura feminina. Trata-se, portanto, de uma grande coleção centrada no presente, com um valor histórico limitado, apesar de tudo.

Ainda que a multiplicidade de enfoques teóricos, ênfases metodológicas e horizontes ficcionais seja notável, é possível identificar, ainda que grosseira e redutivamente, duas tendências dominantes na antologia, que, de novo em linhas gerais, caracterizam duas fases da Teoria nos EUA. A primeira, que poderia ser chamada de textualista, está associada em grande medida à Derrida e à desconstrução; trata-se de uma teoria tecnicamente sofisticada, mais preocupada com aspectos formais da cultura como um todo (a cultura concebida como texto), e aparentemente neutra quanto a preocupações políticas imediatas. Seu período áureo foi o das décadas de 70 e 80. A segunda tendência firmou-se nos anos 90; em vez do texto, ela privilegia a noção de poder, Foucault em vez de Derrida (ainda que combinações sejam possíveis); ela é explicitamente engajada, e defende um universo de interesse específico, seja ele o das mulheres, dos negros, dos chicanos, dos homossexuais ou dos países do chamado terceiro mundo. A relação entre as duas vertentes é complexa e abrange um espectro de posições divergen-

\footnotetext{
${ }^{4}$ Kubek lamenta a ausência dos estudos masculinos (Men's Studies) na antologia, pois "uma ampla seleção de material dos estudos masculinos tem estado disponível nas antologias, pelo menos há uma década" (KUBEK, Elizabeth. "Review". The Journal of the Midwest Modern Language Association, (Iowa City), v. 36, n. 2, Fall, 2003: 73). Leitch (2003: 472) fornece uma resposta para isso em um outro contexto: "Pense na proliferação de escolas e movimentos críticos que se deu nas últimas décadas - nossos tempos pós-modernos - ou na lista crescente de sub-áreas que compóem os estudos culturais hoje (estudos do corpo, estudos da subcultura, estudos de trauma, estudos da brancura [whiteness studies], estudos da comida, e estudos animais, entre muitos outros." (in CAIN, William E. et. al. "Responses from the Editors of The Norton Anthology of Theory and Criticism" [Pedagogy.2003; 3: 468-478].

${ }^{5}$ Aqui surge o adjetivo "literário" pela primeira vez, em um contexto crítico, que facilmente pode levar a ataques a literatura.
} 
tes. Em um extremo há uma posição de conflito, como no texto de Barbara Christian, que critica a teoria pura a partir da perspectiva da negritude. Os teóricos

de fato anunciaram sua insatisfação com algumas das idéias fundantes de sua própria tradição, uma insatisfação com a qual eu nasci. Mas na tentativa de alterar a orientação do saber ocidental, eles, como sempre, concentraram-se em si mesmos e não se mostraram minimamente interessados nos mundos que haviam ignorado ou controlado. De novo, supunha-se que eu deveria conhecer $a$ eles, ao passo que eles não estavam de maneira alguma interessados em conhecer a mim. [...] Como sou levemente paranóica, me veio à mente que a literatura que está sendo produzida é justamente uma das razôes por que esta teoria filosófico-crítico-literária da relatividade é tão proeminente. Em outras palavras, a visão de que literatura dos negros, das mulheres da América do Sul e África etc. é uma literatura "política" estava sendo neutralizada por antecipação por um novo conceito ocidental que proclamava que a realidade não existe, que tudo é relativo, que todo texto silencia a respeito de algo - o que realmente é o caso aqui."

Trata-se de uma lógica de nós versus eles inscrita na própria produção teórica; a dificuldade desta posição, no entanto, fica aparente quando Christian se vê obrigada a diferenciar entre outros "eles":

Não quero dar a impressão de que, ao fazer objeções à corrida pela teoria, ${ }^{6}$ eu esteja me aliando ou concordando com os humanistas neutros, que vêem a literatura como pura expressão e que se recusam a admitir o óbvio controle de sua produção, valor, e distribuição por aqueles que detêm o poder, que negam, em outras palavras, que a literatura é, necessariamente, política.

Ao colocar os "humanistas neutros" como antagonistas últimos, Christian indiretamente configura o campo da Teoria, contra o qual se voltava, mas do qual não deixa de fazer parte.

bell hooks (com letra minúscula mesmo) apresenta uma postura de transição. Ainda que concorde que a Teoria foi formulada - e seja utilizada - por uma elite (branca), vislumbra na desessencialização que promove um potencial positivo:

A crítica ao essencialismo desenvolvida pelo pensamento pós-moderno é útil para os afro-americanos preocupados com a reformulação de noções ultrapassadas de identidade. [...] Empregar a crítica ao essencialismo permite aos afro-americanos reconhecer a forma pela qual a mobilidade social tem afetado a experiência coletiva

\footnotetext{
${ }^{6} \mathrm{O}$ título em inglês tem uma ambigüidade explorada pela autora, pois pode significar "Raça para a Teoria" ou "Corrida pela Teoria".
}

"(Barbara Christian. “The Race For Theory": 2261.)

"(Id., lbid.: 2259.) 
" ("Postmodern Blackness": 2482.)

("From Blues, Ideology, and Afro-American Literature: A Vernacular Theory")

(p. 2230.)

(PATAI, Daphne, CORRAL, Will H. Theory's Empire. An Anthology of Dissent. Nova York: Columbia U.P., 2005.) dos negros, fazendo com que o racismo não tenha necessariamente o mesmo impacto em nossas vidas. Essa crítica nos permite afirmar múltiplas identidades, variadas experiências negras. Ela também questiona os paradigmas coloniais e imperialistas da identidade negra, que representam a negritude de uma maneira unidimensional com vistas a reforçar e manter a supremacia branca.

Por fim, Huston A. Baker Jr. representa o outro extremo do espectro, pois acolhe vivamente as proposiçōes de um certo pós-modernismo nos estudos negros. No texto antologizado, ${ }^{*}$ Baker sugere que o blues pode ser visto como uma matriz de conversão da experiência vernácula negra em cultura. Baker define a matriz como

um útero, uma rede, uma rocha geradora de fósseis, um rastro rochoso deixado por uma gema, o metal principal de uma liga, uma moldura ou forma de reprodução gráfica ou de discos. A matriz é um ponto incessante de entrada e saída [input and output], uma rede de impulsos em interseção e entrelaçamento, sempre em um trânsito produtivo. $\mathrm{O}$ blues afro-americano constitui uma tal rede vibrante. Ele é o que Jacques Derrida poderia descrever como o "sempre já" da cultura afro-americana."

Já o blues, "ao invés de uma forma rigidamente personalizada",

oferece uma recapitulação filogenética - uma meditação livremente associativa e não conceitual - de espécies de experiência. O que surge não é um sujeito preenchido, mas uma voz anônima (sem nome) advinda da totalidade esburacada $[(w)$ hole $]$ negra. A coda de assinatura do cantor de blues é sempre atópica, deslocalizada.

Ora, não é difícil verificar nesses trechos como são resultado da mistura de um núcleo conceitual pós-modernista com um conteúdo da cultura negra. Mas vale a pena se perguntar se o preço pela sofisticação teórica não é uma perda de impacto político, se a adoção do arcabouço pós-moderno não leva à conciliação e ao apagamento do antagonismo, ao passo que o confronto direto, manifestado na fraca e limitadora oposição binária do nós versus eles, não acarretaria uma má teoria. Este é apenas um dos dilemas da Teoria - e há muitos outros.

III

Theory's Empire: An Anthology of Dissent foi publicado em 2005; ' com 725 páginas, apresenta 47 ensaios divididos em oito partes com títulos inequívocos: a. a Teoria ascendente; b. viradas lingüísticas; c. a construção do império; d. Teoria como profissão; 
e. identidades; f. Teoria como substituta da política; g. restaurando a razão; h. ainda lendo, apesar de tudo, estas teorias. Seus autores ocupam um amplo espectro crítico e político; alguns deles, como René Wellek, Todorov ou Elaine Marks, são ex-entusiastas que posteriormente se retrataram, espantados pelos rumos tomados pela teoria, enquanto outros, como Merquior, sempre se colocaram contra a Teoria. A diversidade e o número de contribuiçôes são muito grandes, envolvendo desde os esperáveis calcanhares-deaquiles da Teoria, como o caso Paul de Man e a peça de Sokal, ${ }^{7}$ até idéias inusitadas. Talvez a melhor forma de comentar a coleção seja por meio da simples listagem, em outra ordem, dos argumentos mais importantes. São 26 ao todo:

1. Ao negar as grandes metanarrativas, a teoria na realidade erigiu a maior delas: a própria Teoria.

2. A Teoria está destruindo os estudos literários: ela não distingue tipos de escrita (incluindo a diferença entre obra ficcional e discurso crítico); ela é incapaz de lidar com questôes de valor e verdade, potencialmente igualando pornografia e Goethe (René Wellek).

3. A desconstrução põe fim ao chamado practical criticism, a leitura atenta aos textos em si, porque meramente os usa para corroborar posições já dadas de antemão.

4. A Teoria desconsidera questôes éticas; sua crítica ao humanismo é insustentável.

5. A crítica que se volta para questôes de gênero sexual, raça e classe não está disposta a entrar no debate franco de idéias; ela funciona apenas segundo uma lógica antagonística e partidária, oferecendo interpretações que no fundo são normativas. Para além disso, a Teoria como um todo não propõe argumentos que possam ser refutados, mas enunciados dogmáticos com os quais se deve simplesmente concordar e reproduzir.

6. A Teoria não realiza a leitura cerrada, o close reading, que alimentava o chamado practical criticism. Quando se atém ao detalhe, não respeita a integridade da obra como uma totalidade que determina suas partes. Os fragmentos de textos são retirados de seus contextos e podem querer dizer quase qualquer coisa.

7. A escrita da Teoria é desnecessariamente difícil e obscura.

\footnotetext{
${ }^{7}$ Só para lembrar: o caso Paul de Man refere-se à descoberta em 1987 de artigos racistas escritos pelo autor em 1941 e 1942 em um jornal belga pró-nazista; a peça pregada pelo físico Sokal foi um artigo nonsense, feito de citaçóes de teóricos a respeito da ciência, que foi aceito como sério na revista Social Text.
} 
(Donogue, Denis, Ibid.: 111.)

(SEARLE. "Literary Theory and Its Discontents". Ibid.: $171 ; 149$.

"(DESCOMBES, "The Quandaries of the Referent", Ibid.: 188-189.)
8. Ao perder sua transitividade, por não mais ser teoria de alguma coisa, a Teoria converteu-se em pura instituição, que, "como a Teologia [...] defende argumentos fundacionais, começa com uma determinada razão tida como postulado e a expande em todas as direçôes a partir dela."”

9. A Teoria transforma eventos políticos em ocasiões hermenêuticas.

10. A Teoria suprime o referente; para tanto, ela tem que se fazer cega à natureza dêitica da linguagem.

11. A Teoria é oriunda de uma tradição de pensamento que não contempla os desenvolvimentos mais recentes da filosofia:

Derrida é ele mesmo um filósofo muito tradicional em um sentido que se pode explicar breve e precisamente ao dizer que seu trabalho provém de pressupostos pré-Wittgenstein. [...] Creio que a ignorância de Derrida do lugar comum filosófico de que os conceitos são em geral bem frouxos em suas fronteiras [boundaries] é típica de uma ignorância mais ampla de alguns princípios lingüísticos fundamentais. No que se segue argumentarei que se você passa a compreender alguns princípios e distinçōes fundamentais a respeito da linguagem, então muitas das questôes da teoria literária que parecem ser terrivelmente profundas e misteriosas têm na realidade soluçōes simples e claras."*

12. A "ilusão de um referente último da linguagem em si-daquilo que os dialéticos chamam de o Outro da linguagem - não é uma aparição transcendental. [...] [A] ilusão em questão, reflete, ao invés, a inadequação do paradigma escolhido. Na origem desta ilusão não há nada que seja necessário, somente uma cascata de reduçôes. Todos os signos são tratados como palavras. Todas as palavras são tratadas como nomes. Todos os nomes são tratados como símbolos. O que deve ser criticado não é tanto a "linguagem" ou a "função simbólica", quanto a indiferença de longa data de nossos teóricos contemporâneos àquilo que os gramáticos chamam de $c a-$ tegorias lexicais [parts of speech]."

13. A Teoria forma um clã de iniciados que exclui aqueles que não são capazes de dominar seus complexos sistemas teóricos, ou simplesmente não se interessam em fazê-lo.

14. A Teoria é marcada por um presentismo maléfico; ela é incapaz de ter uma visão do passado ou do futuro: "A cultura da Teoria é neomedieval, e o estilo de seu discurso é neo-escolástico. As citaçôes das autoridades canonizadas é mais importante do que a pesquisa pessoal e a verificação independente. Para a Teoria não há 
individualidade, originalidade ou independência: o prefixo re-domina seu vocabulário, junto com seu par, o post-. Tudo é sempre já uma repetição, uma re-leitura, uma re-escrita. Esse clima de mesmice [staleness] e de tardividade [belatedness] é o resultado paradoxal do presentismo: sem uma narrativa ligando o presente ao passado e ao futuro, não pode haver desenvolvimento, apenas repetição."*

15. "Com o tempo, a suspeita em relação aos universais cobra uma vingança. Apesar da retórica da subversão, ela leva os intelectuais na direção da resignação. Sem uma idéia enfática de liberdade e felicidade, uma sociedade melhor não pode ser vislumbrada; a utopia murcha. Aqueles que celebram a diferença e desacreditam nos universais não conseguem pensar para além das possibilidades imediatas oferecidas pela história; na melhor das hipóteses valorizam tudo que seja curioso ou não-ocidental; na pior, mitologizam práticas questionáveis.”

16. A crença generalizada de que tudo é construído tem conseqüências nefastas: "Na melhor das hipóteses [...] o pensamento construcionista expõe a contingência daquelas práticas sociais que enganosamente encarávamos como inevitáveis. [...] Ele se desvirtua quando pretende se tornar uma metafísica ou uma teoria geral do conhecimento. No primeiro caso, rapidamente degenera em idealismo; no segundo, ocupa um lugar numa longa história de tentativas problemáticas de relativizar a noção de racionalidade.”*

17. A Teoria nos EUA importou problemas que faziam sentido no ambiente intelectual francês, como a famosa morte do autor de Barthes, não facilmente justificável em uma tradição desprovida de academias de letras, com pouca intervenção governamental, e cujas maiores influências foram o empirismo, ligado à linguagem comum, e Shakespeare, o autor por excelência da variedade de registros lingüísticos.

18. A Teoria foi responsável pelo surgimento do star system nas universidades norte-americanas, que tem como contrapartida a proletarização dos outros professores.

19. Um dos pressupostos da Teoria engajada atual é o de que a crítica que silencia a respeito da política reforça necessariamente o status quo. Essa inferência é falsa, porque 1. atribui uma intenção ao autor do ensaio (que nega ao autor da obra); 2. desconsidera o efeito desprezível da produção acadêmica na sociedade; 3 . implica uma noção monolítica de status quo.

20. Embora as novas abordagens de análise literária sejam diretamente motivadas por questôes que estão no cerne do debate po-
"(GOOD, Graham. "Presentism". lbid.: 288-289.)

• (JACOBY, Russell. "Thick Aestheticism and Thin Nativism". Ibid.: 496.)

* (BOGHOSSIAN, Paul A "What is Social Construction". lbid.:573.) 
- (O'CONNOR, Erin. “Prefácio para uma crítica pós-colonial". Ibid.: 298) lítico, a leituras que decorrem dessas abordagens não estimula uma discussão produtiva das idéias, suposiçōes e desejos por detrás delas. A crítica literária, na realidade, não é uma arena adequada para o debate político; ela o desvia para longe do seu alvo.

21. A teoria pós-colonial não respeita a integridade das obras que critica. Ela produz uma inversão espúria: "Seja invocando 'ficção', 'alegoria', 'narração', ou 'texto', cada fórmula explica a dimensão extraliterária da literatura como um processo literário - um procedimento que ao mesmo tempo reifica o literário como um modo de apreensão e torna a literatura como tal peculiarmente inacessível: à medida que a narrativa se torna uma metáfora para um processo ideológico, ela não mais é acessível como uma forma particular de escrita com seus modos e meios singulares e irredutíveis."

22. Seja do ponto de vista do novo pragmatismo, dos Estudos Culturais, ou de uma antropologia textualizada, a Teoria incentiva o escrutínio de tópicos menores, barrando qualquer referência ao geral ou universal. $\mathrm{O}$ estudo da realidade transforma-se em um novo esteticismo, que em última instância é incapaz de julgar.

23. Ao reduzir fatos a valores, e o plano da cultura a questôes de poder, os estudos culturais abolem qualquer espaço para a política, pois o estabelecimento de uma ordem política e legítima fica fora de questão: uma distribuição justa de direitos e recursos ou uma ordenação igualitária das prioridades políticas, por exemplo. Essa fragmentação, no fundo, não expressa um conteúdo libertário; pelo contrário, ela transplanta, para o nível de grupos (maiores ou menores) a ideologia típica do individualismo burguês, do Bellum omnium contra omnes.

24. A Teoria faz um uso mistificado e mistificador das ciências exatas, desvirtuando seu conteúdo.

25. As leituras que a Teoria faz da ciência, criticando-a como veículo de dominação de sexo, raça e classe e vinculando-a ao projeto fracassado do Iluminismo, são elas mesmas obscurantistas e podem contribuir, com seu apelo implícito a um mundo pré-industrial, com movimentos nativistas retrógrados e antimodernos. Esse o resultado da interpretação de Spivak, na Índia.

26. A sexualização de tudo dos queer studies tem como procedimento interpretativo de base a separação de um elemento textual, que é então relacionado a qualquer coisa. A motivação que lhe subjaz empobrece o ser humano: 
Quando reduzimos nossas vidas a 'corpos e prazeres', reduzimos corpos e prazeres a um debate incessante sobre o sentido de nossas vidas. E então reduzimos amor a trabalho, e o trabalho, sem a promessa e recompensa do amor, a uma finalidade sem sentido. E o pior de tudo é que, como o resultado de se tornar a presença física uma fria abstração, começamos a nos tornar indiferentes à - ou então especialistas na - dor física das outras pessoas.

\section{IV}

Sem dúvida, esses argumentos têm um poder de persuasão muito diferenciado. As críticas ao relativismo, particularismo, presentismo e partidarismo são difíceis de ser refutadas; por outro lado, várias outras projetam uma imagem estereotipada e errônea da Teoria, avessa àquilo que ela possui de melhor. Seja como for, tomado como um todo, O Império da Teoria* é marcado por um impulso beligerante que cobra um preço em sérias limitações. Apenas o ensaio de John M. Ellis, "Is Theory to Blame?", levanta a hipótese de que o problema não estaria na teoria em si, mas na má teoria, naquilo que dela foi feito nas mãos de gerações subseqüentes. Nenhum dos argumentos acima poderia ser aplicado, por exemplo, a Fredric Jameson, expoente reconhecido e proeminente da Teoria. Em segundo lugar, o espanto e ultraje diante de uma suposta hegemonia da Teoria, na realidade exagerada, ${ }^{8}$ impedem que se dê a devida atenção às causas de tal preponderância. Se ele existe, tem de haver algum motivo concreto, a não ser que se queira simplesmente chamar a todos os defensores da Teoria, professores universitários, alunos de pós-graduação e de graduação, de estúpidos ou ingênuos. Em toda a antologia há apenas dois argumentos a esse respeito; um deles será mencionado mais adiante; o outro é o de que o ímpeto vanguardista de 68 teria cativado toda uma geração, que hoje ocupa posiçóes-chave na universidade, e que estaria influenciando seus alunos. Isso é muito pouco. Se a Teoria fez tanto sucesso é necessário que haja algo de verdadeiro nela - defender a idéia de pura manipulação das humanidades é zombar da inteligência de gente demais. Se é verdade que a Teoria é obscura e despreza a troca franca de argumentos, ela não entedia como a bem comportada e clara forma de exposição da crítica tradicional ("este ensaio defenderá ' $\mathrm{x}$ ' - por causa de ' $\mathrm{y}$ ' e ' $\mathrm{z}$ ', 'x' é verdadeiro - co-

\footnotetext{
8 "Um Derrida, Fish, Jameson ou Culler pode encher mais auditórios do que qualquer mero escritor ou poeta” (Ibid: 291).
}

* (SIEGEL, Lee. "Queer Theory, Literature and the Sexualization of Everything". Ibid.: 440.)

" [Theory's Empire] 
- (Social Constructionism: Philosophy for the Academic Workplace.) mo vimos, este ensaio defendeu 'x'.") Por fim, O Império da Teoria não se esforça em esconder seu caráter restaurador, reacionário em seu sentido original, como se fosse possível voltar às formas préteóricas de leitura. A última parte da coleção, "Ainda lendo, apesar de tudo, estas teorias", que deveria representar seu lado propositivo em vez de meramente destruidor, é a menos interessante de todas; seus textos não se comparam nem de longe com os clássicos da Teoria, como em um Barthes ou Blanchot.

Fazer tábula rasa da Teoria não é aconselhável - não porque toda interpretação tenha necessariamente uma teoria na qual se baseie, pois não se pode exigir que todo ensaio exprima de onde vem: exibir sua teoria não é o mesmo que se supor ateórica; não porque as opçóes apresentadas sejam frustrantes, ${ }^{9}$ mas simplesmente porque postular uma volta à literatura e às grandes obras é tapar o sol com a peneira e fingir ignorar a grande crise que marca as letras, em todo o mundo, diante da revolução tecnológica do computador, do videogame etc. O papel da Teoria é contraditório, pois se por um lado ela relativiza a importância do literário, que agora passa a existir lado a lado dos cartoons ou do YouTube, por outro fornece um novo fôlego para a leitura de textos que de outra forma poderia perder em interesse. ${ }^{10}$ Vários autores no Império chamam a atenção para o número decrescente de alunos cursando as humanidades nos EUA, e culpam a Teoria por isso; restaria saber se, com a sua ausência, os índices não seriam muito piores. Vistos assim, esses argumentos parecem girar em falso, atacando algo a partir de um lugar que não se sustenta.

Nesse contexto, um ensaio em especial da coleção merece destaque. Em "Construcionismo social: filosofia para o meio acadêmico", Mark Bauerlein* começa caracterizando uma crença que alimenta muito da Teoria atual, segundo a qual, como todo conhecimento é uma construção: o que existe são conhecimentos diferentes, com o mesmo grau de relatividade, de forma que não é possível

${ }^{9}$ Como no caso de Freadman \& Miller, antologizado em O Império da Teoria, que propõe um modelo ético de leitura, a partir de uma noção substantiva do humano (FREADMAN, Richard, MILLER, Seumas. Re-pensando a teoria: uma crítica da teoria literária contemporânea. São Paulo: Editora da Unesp, 1994).

${ }^{10}$ Isso fica claro no comentário de Jonathan Culler (CULLER, Jonathan. Teoria Literária: uma introdução. Trad. Sandra Guardini. T. Vasconcelos. São Paulo: Beca, 1999: 53-55), de que nunca se escreveu tanto sobre Shakespeare, mas nunca se teve tão pouco interesse pelos outros escritores elizabetanos. A pergunta que fica, claro, é em que medida o conhecimento destes não seria uma precondição para a compreensão daquele. 
lhes transcender para se chegar a alguma espécie de objetividade. A escolha entre uma ou outra construção passa a ser moral; a verdade é substituída pela tática. O ponto forte do texto é conectar essa concepção errônea com o modus operandi da academia norteamericana dos dias de hoje:

Esta é a vantagem simples e banal do construtivismo social: ele economiza tempo. Verdade, fatos, objetividade - eles exigem leitura demais, visitas demais à biblioteca, tempo demais solicitando materiais de outras bibliotecas, investigando microfilmes, conferindo fontes e projetando-se para além de modas acadêmicas que vêm e vão. Uma filosofia que desautoriza as fundaçôes dessa pesquisa demorada é uma benção profissional. É o sistema de crenças dos pesquisadores que precisam de um álibi para não ler aquele livro a mais, para viajar para os arquivos, ou dar ouvidos a outros pontos de vista. Eis porque o construcionismo representa o credo predominante nas humanidades hoje. Ele é a epistemologia da pesquisa com pressa, dos professores sob pressão, sob a mira do revólver.

Ou seja, a indiferenciação das construções adequa-se muito bem ao ímpeto produtivista da universidade contemporânea. E o mesmo pode ser dito em relação ao discurso da pós-moderno da abundância, ' dos trans- (transdisciplinaridade, transculturalidade...) e multi- (multiculturalismo etc.), que de antemão dispensam um discernimento agudo, além do confronto e do antagonismo. Se isso for verdadeiro, então haveria um tipo de prática teórica que estaria mais adequada ao modo de produção acadêmica norte-americano. ${ }^{11}$

Em um pequeno grande livro de 2004, Lindsay Waters, Editor Executivo da Cambridge University Press para a área de humanas, caracterizou bem a crise pela qual passa a academia norteamericana ao defini-la como uma crise de superprodução de textos - que ninguém compra e ninguém lê. Os números de fato são assustadores: em 2000 as editoras universitárias estadunidenses publicaram nada menos do que 31 milhões de livros, enquanto a média do número de exemplares vendidos por edição caiu de 1.250 para 275 nos últimos trinta anos. Essa explosão e a paralela perda de relevância da pesquisa têm como causa a quantificação do julgamento, que por sua vez se origina na reforma administrativa das universidades, desde então conduzidas mais por executivos do que

\footnotetext{
${ }^{11}$ A universidade compartilharia, assim, de uma tendência social geral de superprodução semiótica do capitalismo tardio. Sua excessiva geração de sentido não destoa do bombardeamento que todos sofrem, cada vez mais, no cotidiano de qualquer cidade minimamente tecnologizada, e que converte o silêncio em mercadoria de luxo.
}

(lbid.: 353.)

(DURÃO, Fabio Akcelrud. "A postmodern paradox". Ipótesi, Juiz de Fora, no prelo.)

-(WATERS, Lindsay. Enemies of Promise. Publishing, Perishing and the Eclipse of Scholarship. Chicago: Prickly Press, 2004: 7-36.) 
por acadêmicos. Quando para se conseguir tenure, a estabilidade no emprego depois de um período probatório de sete anos, é necessário ter ao menos um livro publicado, independentemente do que esteja contido nele, a máquina acadêmica não pode senão inchar. Ora, a Teoria foi, além de outras coisas, um meio pelo qual se pôde ressignificar tudo o que havia, muitas vezes ignorando-se o que já havia sido dito antes. Shakespeare pôde ser relido (i.e. reescrito, publicado) segundo arcabouços femininos/feministas, queer, pós-coloniais, do New Historicism, da pragmática, dos media studies etc. Mas não apenas ele; também os telejornais e o heavy metal e as latrinas e a MTV. Waters termina seu livro com um apelo a novas e ousadas teorias, pois considera que as atuais (seus alvos são Stanley Fish e Richard Rorty) têm, na realidade, uma natureza antiteórica, conformista e, em última instância, normativa; como se viu, um dos argumentos contra a Teoria. A conclusão que Waters deixa entrever, sem explicitar, é a de que o sistema universitário norte-americano gira em falso, que produz discursos desvinculados da sociedade como um todo, e que ele mesmo não consegue absorver o que produz.

O debate em torno da Teoria nos EUA acende um grande sinal de aviso para o Brasil. Sem dúvida, nossos pró-reitores e reitores ainda não são burocratas formados em management, mas a pura quantificação da avaliação já está instalada aqui por meio dos sistemas governamentais de avaliação - com a anuência e a participação da comunidade acadêmica - e é previsível que a Teoria possa vir a desempenhar (se já não estiver desempenhando) um papel similar na renovação problemática da produção de enunciados sobre a literatura e cultura. Note-se bem, não se trata de reduzir o debate da Teoria à materialidade de seus espaços de enunciação, mas de chamar a atenção para o quanto a consciência a respeito das condiçōes concretas da produção intelectual pode ajudar a se evitar os giros em falso do debate da Teoria - menos para que isso leve a mais outra posição teórica do que para a transformação de tais condições. 


\section{Fabio Akcelrud Durão}

Formou-se magna cum laude em Português/Inglês pela UFRJ, e obteve o mestrado em Teoria Literária pela UNICAMP. Seu doutorado foi feito na Duke University, onde estudou com Frank Lentricchia e Fredric Jameson. Publicou Modernism and Coherence (Peter Lang, 2008), além de diversos artigos no Brasil e no exterior nas áreas de teoria literária e crítica da cultura. Seus interesses de pesquisa incluem a Escola de Frankfurt, o modernismo de língua inglesa e a teoria crítica brasileira.

\section{Resumo}

O presente texto investiga uma faceta da atual crise dos estudos literários, manifestada na transição entre a teoria literária para a Teoria. Através do confronto de duas recentes obras, que se tornaram referência no debate norte-americano, o ensaio chama a atenção para os avanços conceituais inegáveis promovidos pela Teoria, que, no entanto, ocorrem em meio a uma crescente alienação e potencial filistinismo. $\mathrm{O}$ artigo termina com observaçôes a respeito da adequação de certo discurso teórico ao modo de produção acadêmico de hoje - cada vez mais quantitativo.

\section{Abstract}

This paper investigates the current crisis of literary studies as it is expressed by the transition from literary theory to Theory. Comparing two recent works, which became important references in the debate in the United States, this essay calls attention to the undeniable conceptual progress brought about by Theory, which, however, took place amid an increasing alienation and potential philistinism. This article ends with remarks on how certain theoretical discourses fit into the current academic mode of production - more than ever ruled by quantitative parameters.

\section{Résumé}

Ce texte analise une facette de la présente crise des études littéraires, manifeste dans la transition entre la théorie littéraire et la Théorie. Par le biais de la confrontation entre deux oeuvres récentes, qui sont devenues référentielles dans le débat nord-américain, cet essai attire l'attention sur les avancées conceptuelles indéniables promues par la Théorie, qui ont pourtant lieu parmi une aliénation croisssante et un philistisme potentiel. Cet article termine sur des observations à propos de l'adéquation d'un certain discours théorique au mode de production académique d'aujourd'hui - de plus en plus quantitatif.
Palavras-chave: Teoria; teoria literária; Norton Anthology of Theory and Criticism; Theory's Empire; modo de produção acadêmico.

Key words: Theory; literary theory; Norton Anthology of Theory and Criticism; Theo$r y$ 's Empire; academic mode of production.

Mots-clés: Thérie; théorie littéraire; Norton Anthology of Theory and Criticism; Theory's Empire; mode de production académique.

Recebido em 01/02/2008

Aprovado em 10/03/2008 